\title{
How Spelling Reform Would Promote Better Writing and Speaking
}

COMMUNICATION CORNER No. 24

\author{
by Philip Yaffe
}

\section{Editor's Introduction}

Each "Communication Corner" essay is self-contained; however, they build on each other. For best results, before reading this essay and doing the exercise, go to the first essay "How an Ugly Duckling Became a Swan," then read each succeeding essay.

Instead of mastering the chaos of learning to read and write in English, perhaps we should start spelling things the way they sound. 


\title{
How Spelling Reform Would Promote Better Writing and Speaking COMMUNICATION CORNER NO. 24
}

\author{
by Philip Yaffe
}

I know what I am about to say may seem to be somewhat off the wall. However, the more I think about it, the more I am convinced that a major reason most people write and speak so poorly is the chaotic state of English spelling.

Why should spelling affect writing and speaking?

Because, except for impromptu speeches, most people probably write out what they are going to say before they actually say it. The longer the speech, the more likely this is to be true.

It seems evident the more you must concentrate on the correct form of the words you use, the less you can concentrate on how best to use them, i.e. putting them together in clear, concise, persuasive sentences and paragraphs.

This diversion of attention occurs not only when one is actually writing, but also when proofreading. The need to find and eradicate spelling mistakes inevitably distracts from what should be your principal concern when proofreading, i.e. ensuring you have produced a clear, concise, and effective text.

But this is only one reason why English spelling is inimical to good writing and speaking.

We have all already spent years in school learning how to spell correctly when the same time could have been more profitably spent on learning how to write correctly. Do you remember those incessant "spelling bees"? Disguised as games and competitions, their real purpose was to help children master the language's thoroughly chaotic misuse of the alphabet.

We are all familiar with irregular spellings, i.e. words that don't seem to follow the general rules of pronunciation, such as "write" (silent w), "island" (silent s), "right" (pronounced "rite"), "rough" (pronounced "ruf"), "through" (pronounced "thru"), and so on. In school we had to learn and memorize these and many other such oddities at the risk of being marked down or getting a failing grade. 


\section{WHY HOMOPHONES?}

Irregular spellings are not the only thing that make written English so difficult for native speakers-and even more so for foreigners - to master. Compared to many other languages, English is also littered with an extravagant number of homophones. These are words that are pronounced the same, but spelled differently.

I recently experienced this problem at a dramatic extreme. I live in Brussels. An acquaintance whose native language is French asked if I could help her learn the lyrics of several songs that were going to be used in her choral group. After about an hour of effort, she had more or less learned only four lines because the words she was seeing on the page were so different from how I was telling her they were pronounced. Finally, we decided the only solution was for me to record the lyrics so she could read them and hear how they were pronounced at her leisure.

If you find this difficult to comprehend, consider the following:

A. As I was writing this sentence, I realized that after having read it, the reader would have a perfect right to criticize its spelling.

B. As eye was righting this sentence, I realized that after having red it, the reader would have a perfect write to criticize its spelling.

Sentence A is of course correct while sentence B is full of homophonic errors. Now read the two of sentences aloud. You won't be able to tell them apart because they will sound exactly same. So the question is: Why do we need these homophones?

The easy answer is, because we normally don't read aloud; therefore, we have to spell words like "eye" and "I," "right" and "write," "here" and "hear," "there" and "their," "see" and "sea," etc. differently in order to distinguish them. Right?

Wrong. If this were the case, we would then write "read" (pronounced "reed") differently from "read" (pronounced "red"), "lead" (pronounced "leed") differently from "lead" (pronounced "led"), "project" (pronounced "praw-ject") differently from "project" (pronounced "pro-ject"), etc.

It can be argued these are among a very few exceptions that simply need to be learned. However, the argument doesn't stand up because of the widespread use of homographs. Homographs are words that are spelled the same and pronounced the same but have very different meanings.

Look in any dictionary and you will find dozens of homographs on virtually every page. As only one example, take the common word "bed." My Webster's Dictionary lists the following definitions: 
1. A piece of furniture for sleeping or resting on

2. A plot of soil where plants are raised

3. The bottom or a lake, river or ocean

4. Any flat surface used as a foundation

5. A geologic layer or stratum

6. The flat surface of a truck

Or how about "flat"?

1. Having a smooth, level surface

2. Lying spread out

3. Broad, even, and thin

4. Insipid, tasteless

5. Uninteresting

6. Steady, not fluctuation (flat rate of interest)

7. Absolute, unequivocal (flat denial)

8. Below true pitch (music)

The fact is the majority of English words have at least two or more distinct definitions for exactly the same spelling. If we can happily live with these, then why do we single out a large number of them to have different spellings for different meanings?

Even with more than 50 years of writing experience, I still occasionally trip over homophones. Sometimes I write "there" when I mean "their," "site" when I mean "cite," "die" when I mean "dye," etc. I usually catch and correct these mistakes in proofreading, but it takes a bit of effort. More importantly, every time I use a homophone, I have to stop for a nanosecond to be certain I have chosen the correct spelling. A nanosecond's hesitation once or twice in a text probably won't do much harm. But 10-20 nanoseconds ever page almost certainly will.

\section{BACK TO BASICS}

There is another, deeper reason for eliminating irregular spellings, homophones, and other such oddities.

In human history, writing of course developed long after speaking, with the purpose of capturing human speech for later use. It was only when man invented "literature" that writing took on a personality of its own. Once it became a kind of art form, divergence of the written language from the spoken language was not only increasingly accepted, in some quarters it was actively encouraged. 
But most of us are not artists; we don't write literature. When we put pen to paper, our objective is to communicate. To say what we have to say clearly, concisely, effectively.

It can be argued anything that distracts us from what we are trying to say, such as the form of the words we use, is counterproductive. Time spent worrying about correctly spelling words is time taken away from considering which words we should be using and how to put them together into clear, concise, effective sentences.

A number of other languages seem to have understood this message. Spanish, for instance, is close to being phonetic. In general, if you can say a word, you can spell it, and vice versa. German comes even closer to being phonetic.

True, the basic grammar of many other languages is considerably more complex than English grammar. But at least these languages have recognized the futility of non-phonetic spelling and have largely done away with it.

\section{RIDING THE CULTURAL CONVEYOR BELT}

Despite its manifest disadvantages, it is amazing how fiercely some people struggle to preserve English's chaotic spelling.

A principal defense of the status quo is that current spelling acts as "a conveyor belt of culture." Thus, we write "pharmacy" with "ph" to remind us that the word is derived from Greek, and we write "farmer" with an "f" to remind us that this word isn't. But why should the way we spell a word reflect its origin?

If language is for communication, it should avoid useless complications such as non-phonetic spelling. "Phonetic" itself should be spelled with an " $f$ " as it is in Dutch (fonetiek), Italian (fonetico), and Spanish (fonético). Its Greek origin is of interest mainly to linguists, but it shouldn't be imposed on the rest of us each and every time we sit down at the keyboard.

Besides, do we actually need to spell words of Greek/Latin origin differently in order to recognize them?

Italian, the modern language closest to Latin, doesn't seem to feel this compulsion. In addition to spelling "phonetic" as fonetico, it also happily spells words like "hydraulic" as idrolico rather than "hydrolico," "synchronous" as sincronico rather than "syncronico," "sympathy" as simpatia, "symphony" as sinfonia (note that both the " $\mathrm{y}$ " and "ph" have disappeared), etc. Anyone who knows anything about languages would recognize these words to be of Greek/Latin origin without having the fact incessantly hammered into their heads by special spellings. 


\section{LET'S GET REAL}

When the written language loses touch with the spoken language, i.e. becomes unnecessarily complicated, it also loses touch with reality. By spelling things the way they sound, we not only make life easier, we remain truer to the reason for which writing was developed in the first place.

Even the Académie Française, the august body that more or less officially regulates the French language, now permits elimination of I'accent circonflexe $\left({ }^{\wedge}\right)$, a diacritical mark that often serves only to remind us 300 years ago the word used to contain an " $\mathrm{s}$ " that is no longer there. For example, in the shift from old French to modern French, isle became île, forest became forêt, intérest became intérêt, etc. Numerous other reforms are also being introduced to make French more logical and less of a barrier to clear communication.

When the Académie was considering removing l'accent circonflexe, I had a discussion about it with a French friend of mine. He was horrified. We debated the reasons for the proposed changes. One by one he lost all logical arguments for retaining l'accent circonflexe. His last line of defense was: "But it looks so good on the page."

If this sounds like a typically French attitude, be assured that it isn't. An article I read opposing spelling reform in English concluded with an equally startling statement: "Spelling is beautiful. Believe it."

Spelling is not beautiful; it is a tool. As with any tool, loading it with useless complications can only reduce its effectiveness, not enhance it. In writing and speaking, the only thing that is beautiful is a well-structured, well-crafted text. Judging a text by how well the author masters chaotic spelling is like judging a painting by how well the artist works with defective brushes.

Am I therefore advocating a massive overhaul of English spelling? Yes, but not immediately. No one would accept such a major change instantly. Even if they recognized the benefits, for many people it would be too much like work. Hardly anyone ever says so, but this is probably the single strongest reason the United States is still fending off the metric system while virtually every other country in the world has recognized its logic and is now happily using it.

Even though it won't happen overnight, given that English is becoming de facto (if not de jure) the world's common language, we should seriously begin looking at how to make it easier to learn and use. Eliminating irregular, non-phonetic spellings would be a good place to start. Not only would this ease the task of others learning the language, it would help everyone-native and non-native speakers alike-to more effectively express themselves clearly and concisely in both writing and speaking.

This would certainly be of immense benefit the world over. 


\section{About the Author}

Philip Yaffe was born in Boston, Massachusetts, in 1942 and grew up in Los Angeles, where he graduated from the University of California with a degree in mathematics and physics. In his senior year, he was also editor-in-chief of the Daily Bruin, UCLA's daily student newspaper. He has more than 40 years of experience in journalism and international marketing communication. At various points in his career, he has been a teacher of journalism, a reporter/feature writer with The Wall Street Journal, an account executive with a major international press relations agency, European marketing communication director with two major international companies, and a founding partner of a specialized marketing communication agency in Brussels, Belgium, where he has lived since 1974. He is the author of more than 30 books, which can be found easily in Amazon Kindle.

DOI: $10.1145 / 3388714$ 